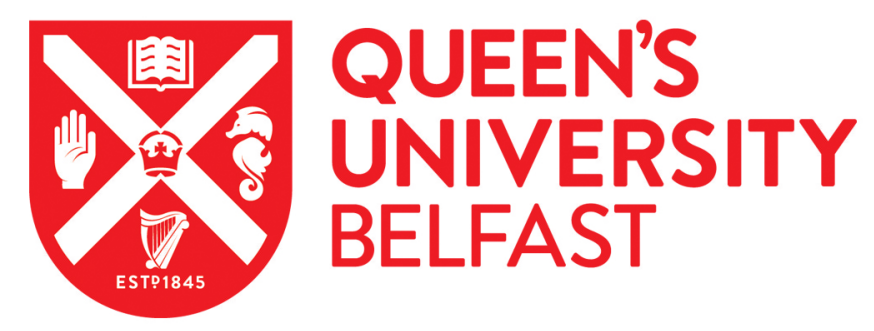

\title{
Patients' perceptions of an exercise programme delivered following discharge from hospital after critical illness (the Revive Trial)
}

\author{
Ferguson, K., Bradley, J. M., Blackwood, B., McAuley, D. F., \& O'Neill, B. (2017). Patients' perceptions of an \\ exercise programme delivered following discharge from hospital after critical illness (the Revive Trial). Journal of \\ Intensive Care Medicine. https://doi.org/10.1177/0885066617724738
}

Published in:

Journal of Intensive Care Medicine

Document Version:

Peer reviewed version

Queen's University Belfast - Research Portal:

Link to publication record in Queen's University Belfast Research Portal

Publisher rights

(C) 2017 The Authors.

This work is made available online in accordance with the publisher's policies. Please refer to any applicable terms of use of the publisher.

\section{General rights}

Copyright for the publications made accessible via the Queen's University Belfast Research Portal is retained by the author(s) and / or other copyright owners and it is a condition of accessing these publications that users recognise and abide by the legal requirements associated with these rights.

Take down policy

The Research Portal is Queen's institutional repository that provides access to Queen's research output. Every effort has been made to ensure that content in the Research Portal does not infringe any person's rights, or applicable UK laws. If you discover content in the Research Portal that you believe breaches copyright or violates any law, please contact openaccess@qub.ac.uk. 


\section{$\underline{\text { Title }}$}

Patients' perceptions of an exercise programme delivered following discharge from hospital after critical illness (the REVIVE Trial)

\section{$\underline{\text { Acknowledgements and credits }}$}

The authors wish to thank our patient representatives from the critical care patient liaison group $(\mathrm{CritPaL})$ who reviewed the interview schedule for this study.

$\mathrm{KF}$ and $\mathrm{JMB}$ are joint first authors. $\mathrm{BB}$ and $\mathrm{BO} \mathrm{O}^{\prime} \mathrm{N}$ are joint senior authors. All authors contributed to the development of the study protocol and semi-structured interview schedule. $\mathrm{BB}$ conducted the interviews. KF transcribed and completed analysis of all data. JMB completed additional independent analysis. KF and JMB wrote the manuscript and all authors contributed to the revision of the manuscript and approved the final manuscript for submission.

\section{$\underline{\text { Authors }}$}

Kathryn Ferguson, $\mathrm{PhD}$, Centre for Health and Rehabilitation Technologies, Ulster University, Northern Ireland mcdowell-k3@email.ulster.ac.uk

Judy M Bradley, PhD, Centre Experimental Medicine, School of Medicine, Dentistry \& Biomedical Sciences, Queen’s University Belfast, Northern Ireland, judy.bradley@qub.ac.uk 
Daniel F McAuley, MD, Centre Experimental Medicine, School of Medicine, Dentistry \& Biomedical Sciences, Queen's University Belfast, Regional Intensive Care Unit, Royal Victoria Hospital, and Northern Ireland, and Northern Ireland Clinical Trials Unit, d.f.mcauley@qub.ac.uk

Bronagh Blackwood, PhD, Centre Experimental Medicine, School of Medicine, Dentistry \& Biomedical Sciences, Queen’s University Belfast, Northern Ireland b.blackwood@qub.ac.uk

Brenda O’Neill, $\mathrm{PhD}$, Centre for Health and Rehabilitation Technologies, Ulster University, Northern Ireland b.oneill@ulster.ac.uk

\section{Funding}

The REVIVE RCT was funded by REVIVE, a charity of the Regional Intensive Care Unit, Northern Ireland. Additional funding provided by the Health and Social Care Research and Development Office, Northern Ireland. The funders had no role in study design, data collection, data analysis, data interpretation, or writing of the report. This trial was also supported by the Northern Ireland Clinical Research Network (NICRN) (Critical Care and Respiratory Health interest groups) and the Northern Ireland Clinical Trials Unit (NICTU) a UK Clinical Research Collaboration (UKCRC) registered clinical trials unit.

\section{Corresponding author}

Correspondence should be addressed to Dr Brenda O'Neill, Centre for Health and Rehabilitation Technologies (CHaRT), Institute of Nursing and Health Research, School of Health Sciences, Ulster University, Newtownabbey, BT37 0QB, UK. 02890368812 b.oneill@ulster.ac.uk 


\section{Patients' perceptions of an exercise programme delivered following discharge from hospital after critical illness (the REVIVE Trial)}

\section{$\underline{\text { Abstract }}$}

Background: The REVIVE RCT investigated the effectiveness of an individually tailored (personalised) exercise programme for patients discharged from hospital after critical illness. By including qualitative methods we aimed to explore patients' perceptions of engaging in the exercise programme.

Methods: Patients were recruited from general intensive care units in six hospitals in Northern Ireland. Patients allocated to the exercise intervention group were invited to participate in this qualitative study. Independent semi-structured interviews were conducted at six months after randomisation. Interviews were audio recorded, transcribed and content analysis used to explore themes arising from the data.

Results: Of 30 patients allocated to the exercise group 21 completed interviews. Patients provided insight into the physical and mental sequelae they experienced following critical illness. There was a strong sense of patients' need for the exercise programme and its importance for their recovery following discharge home. Key facilitators of the intervention included supervision, tailoring of the exercises to personal needs, and the exercise manual. Barriers included poor mental health, existing physical limitations and lack of motivation. Patients' views of outcome measures in the REVIVE RCT varied. Many patients were unsure about what would be the best way of measuring how the programme affected their health.

Conclusions: This qualitative study adds an important perspective on patients' attitude to an exercise intervention following recovery from critical illness, and provides insight into the 
potential facilitators and barriers to delivery of the programme and how programmes should be evolved for future trials.

Trial Registration: NCT01463579 https://clinicaltrials.gov/ Registered 8 September 2011

\section{$\underline{\text { Key Words }}$}

critical care; ICU survivors; perceptions; exercise; qualitative research; patient satisfaction 


\section{Patients' perceptions of an exercise programme delivered following discharge from hospital after critical illness (the REVIVE Trial)}

\section{Background}

Following discharge from hospital after critical illness, patients suffer from reduced physical function, exercise capacity, health-related quality of life and increased healthcare utilisation, which may continue for up to 5 years following discharge from hospital. ${ }^{1-4}$ Trials evaluating exercise-based rehabilitation interventions following discharge from hospital after critical illness have shown discordant results, and currently the optimum structure and content of rehabilitation for this population is unknown. ${ }^{5-14}$ Lack of qualitative components to explore patients' perceptions of rehabilitation in these studies means it is difficult to explore reasons for discordant results. One study has explored patients' perceptions of an exercise intervention using focus groups, which emphasised psychosocial benefits which were not apparent from the quantitative measures alone. ${ }^{15}$ The inclusion of a qualitative component alongside randomised controlled trials (RCTs) is important in order to provide important data for enabling a better understanding of the intervention and trial outcomes. ${ }^{16,17}$

We recently undertook a RCT to investigate the effectiveness of an individually tailored (personalised) 6 week exercise programme for patients discharged from hospital after critical illness (The REVIVE trial). ${ }^{14}$ There was no statistically significant difference in the primary outcome measure of self-reported physical function following this six week exercise programme, however, there were encouraging significant improvements in some, but not all secondary outcome measures. We included qualitative methods alongside this RCT to explore ICU survivors' perceptions of engaging in the 6 week exercise programme. Our specific research objectives were to explore patients' satisfaction with the exercise 
programme, perceptions of physical and psychological effects of the programme, views about continuing exercise, and perceptions of the outcome measures used in the trial.

\section{Methods}

\section{Design}

This qualitative study recruited the patients from the exercise intervention group of the REVIVE trial. ${ }^{14}$ Patients were recruited from six intensive care units in Northern Ireland. Patients completed one individual face-to-face interview, or via telephone if necessary, at their 6 month follow-up time point (6 months following randomisation) using a semistructured interview guide. As previously reported the time taken to complete the exercise intervention ranged from 6 to 11 weeks $^{14}$, therefore interviews were conducted approximately 13 to 18 weeks following the end of the intervention. Ethical approval was obtained from the Northern Ireland Research Ethics Committee. Written informed consent for the interviews was obtained from each patient. If a patient declined or was not interviewed the reason for this was recorded. This manuscript adheres to the consolidated criteria for reporting qualitative studies (COREQ) guidelines. ${ }^{18}$

\section{Data collection}

A draft schedule for the semi-structured interviews was developed by the authors, and face and content validity was confirmed by the wider research team and patient representatives. Table 1 provides an outline of the interview schedule. Interviews were conducted by a trained member of the research team (BB) not involved in the intervention delivery or blinded outcome assessment. 


\section{Data Analysis}

Interviews were audio recorded, transcribed verbatim and content analysis used to explore themes arising from the data. Qualitative analysis procedure based on Burnard's description of thematic content analysis ${ }^{19,20}$ was used as the theoretical framework for analysis [see Additional file 1]. The analysis of all interviews was conducted by KF. A random selection of approximately half of these were analysed independently by a second researcher (JMB). A consensus on emergent themes was reached between all authors.

\section{$\underline{\text { Results }}$}

The findings were drawn from the analysis of interviews of 21 patients (Figure 1). Characteristics of interviewed patients were similar to the total intervention group in the REVIVE trial (Table 2). Interviews were completed face-to-face by 14 (67\%) patients, and 7 (33\%) by phone call. Interviews lasted an average of 25 minutes per patient. Two patients requested their spouses to be present during the interview and they contributed data to the interviews. Seven core themes were identified in the analysis of the interviews.

[Table 2]

\section{Core theme 1: Sequelae of critical illness and critical care recovery}

Although this was not a key aim of the study, the sequelae of critical illness and the critical care recovery pathway emerged as a consistent core theme among patients. Physical and mental sequelae were diverse and significant. Physical sequlae included muscle wasting 
and weakness, weight loss, difficulties with walking, breathing difficulties, problems with hand function and fatigue.

"I was very weak when I came out, I had lost about two and a half stone, my muscles had wasted away.”

Patients reported feelings of depression, mental isolation, low self-confidence, mood swings, poor memory, paranoia, frightening nightmares and hallucinations.

“There was a lot of mental anguish went on in my head, through my case, and I brought that all out, home with me."

On the wards and after discharge home patients felt that there was a lack of support for their specific needs.

"But when I approached my GP after, he was very dismissive and I think it was just genuinely through not enough knowledge.”

\section{Core theme 2: Satisfaction and endorsement of the exercise programme}

Satisfaction with the exercise programme was a consistent theme. The programme was described by patients as "something special", "amazingly good" and "fantastic", and it provided feelings of motivation and hope. Patients stated that the programme gave them "something to look forward to", "a routine", and "an incentive to recover". There was a strong sense of patients' need for the exercise programme and its importance for their 
recovery. Patients described how attending the exercise programme overcame a sense of abandonment that they had felt. Participants expressed surprise that the exercise programme was not part of usual care, and some suggested that they did not feel that they would have coped with their recovery without it.

"I would definitely recommend it. It’s just vital."

“There wasn't anything like this before?...Well I don't know how they managed without it, really... I just couldn't have.”

\section{Core theme 3: Beneficial impact of the exercise programme on physical and} psychological health

The majority of patients reported the programme had a beneficial impact on health and wellbeing. Both patients and their family members felt that their rate of recovery was speeded up by the programme, especially compared with what health professionals had initially indicated. Many stated they would have felt abandoned, and not have improved without the motivation and self-confidence provided by the programme. The benefits reported were predominantly focused on patients' physical health, including mobility, muscle strength, fitness levels, breathing, and earlier return to work. Improvements to patients' physical appearance, appetite and body weight were also reported as a result of the programme.

"I said to her if I hadn't have come to these, for the six weeks of the trial, I'd have still been struggling to get off a chair.” 
Although benefits to physical health were discussed prominently, in some patients a positive impact on mental health was also apparent. The programme appeared to provide some patients with a mental lift, and a different outlook for the future.

“I just feel full of life. I can't wait for tomorrow, you know... Before it was just day after day, but now it's- I'm looking forward to tomorrow."

Many patients acknowledged that they did not always feel like doing exercise at the beginning of the programme. However, the attendance at, and completion of the sessions gave participants an "instant boost" to their mood. Observable improvements in physical abilities during the programme in turn appeared to impact positively on mental health and provided motivation to continue. Patients discussed feeling more confident in activities of daily living which facilitated a sense of independence and decreased reliance on family members and carers.

\section{Core theme 4: Facilitators of beneficial impact}

Patients identified key facilitators of beneficial impact from the exercise programme, such as supervision of exercise, tailoring of the programme to personal needs, and the patient exercise manual. Supervision appeared to be the most important facilitator of perceived benefit. The health professional's guidance and explanation increased patients' confidence and ensured feelings of safety, especially at the beginning of the programme when some patients reported being wary of doing exercise. A health professional that could empathise with their critical care experience and common problems faced by others in their position was considered important. Patients felt that the rapport they had with the physiotherapist was 
motivating, they enjoyed coming to the sessions, having conversations and engaging with someone familiar.

"To have [the physiotherapist] explaining everything to me and making sure that, I knew then I could trust her that if she was pushing me that wee bit further... I felt safe with her doing that, whereas if I had gone on my own and went on a treadmill, I wouldn't have stuck it."

The tailoring of the exercise to personal needs also appeared to be important. It was clear that patients felt that the exercises were 'geared' to their own individual level, irrespective of baseline ability.

“...so they tailored it to my needs and I'd say anyone else's needs who would come along they would do the same."

The patient exercise manual was deemed to be useful, to supplement the instruction and guidance from the health professional and was deemed especially important by patients who had poor memory, and for use at home during unsupervised sessions. Patients thought that the exercise manual had been "well thought out" and "easy to follow". A small number of patients with higher fitness levels felt that the programme was initially too basic for their abilities, but commented that the physiotherapist personalised their programme to meet their individual needs.

\section{Core theme 5: Barriers to beneficial impact}


Although barriers were less prominent than the positive aspects of the programme, some patients did discuss important barriers to the beneficial impact of the programme. Mental health as a sequlae following critical illness appeared to be the main barrier to beneficial impact of the programme.

"I got very down, depressed, half way through the programme."

For some patients, these problems impacted on their ability to participate in the programme and the outcome of the programme causing them to lose focus and self-motivation.

"My mind just wasn't on it”

"It was hard to judge, you know, the effect of it (the programme) and the physical effect of it (the programme), because I sort of became withdrawn, and like I say the mental effects overweighed the physical”

Existing physical limitations, for example walking difficulties and back pain, were other barriers to beneficial impact of the programme for a small number of patients.

\section{Core theme 6: Challenges to continuing exercise after the 6-week programme}

Patients found it difficult to continue exercising at the same level as during the supervised programme. The perceived challenges to continuing exercise after the exercise programme ended were similar to the barriers patients faced during the programme. The main barrier to continuing exercise appeared to be lack of self-motivation when the supervised intervention period was over. Factors influencing this were on-going health problems, fatigue, and lack of time after their return to work. Patients also reported that they felt some positive physical benefits of the programme were lost, for example muscle strength. The 
majority of patients reported that the diary section of the exercise manual relating to continuing exercise was rarely used. Many patients indicated that the exercise programme needed to be longer than 6 weeks. Patients suggested that "booster sessions" to support the continuation of exercise or physical activity and maintain benefits gained would be important.

A small proportion of patients stated that they continued to exercise or became more physically active after the programme and that health benefits continued for some. Patients acknowledged that further independent exercise was not always to the same intensity as during the supervised programme. Facilitators of continuing exercise for these patients included the patient exercise manual, the motivation provided by the programme and the continued support of family.

“He's out walking. Okay he has a stick, but he never walked beforehand. Now he's out making the effort because he knows he has to keep active...the family is very impressed with it.” (Partner)

“Well once you have been taught how to do those exercises, you know, you don't forget about them ever. Because you have been doing them so many weeks on the course."

\section{Core theme 7: Contrasting views on outcome measures}

There were some general positive comments from patients on the outcome assessment. These included that outcome measures were appropriate, insightful, and captured their improvements. 
"...the things with the research nurse like measuring and stuff, like the strength of your hands, it was interesting just to sort of show you that you were not imagining, like I wasn't imagining the weakness in my hands.”

Greater detail was provided relating to negative aspects of the outcome measures by other patients. These were mostly directed toward the questionnaires. Some participants felt the questions were repetitive across the different questionnaires. Patients also stated that the different instructions for completion of the questionnaires were confusing.

"There was quite a lot entailed in those questionnaires you know... and some of them were the same sort of question just in a different sort of a way."

One participant felt that the questionnaires did not seem to cover topics important to her such as sleep patterns and flashbacks. Others stated that some of the questions were too basic for their levels of ability. One participant also commented that day to day changes may not be picked up appropriately. Some participants highlighted that they were not provided with their results or told if they had improved.

"But you could be having a really good day the day you go up, and then when the course finished you would be having a really bad day and, you know, it mightn't look as if you've really improved.”

Patients were asked about the best way to measure the impact of the programme on their health. Many patients did not know, but some patients reported that getting back to 
previous health and life activities was a key goal, and therefore outcomes that would reflect this were of key importance.

\section{$\underline{\text { Discussion }}$}

This qualitative study that accompanied an RCT of an exercise programme for survivors of critical illness (The REVIVE trial) provides new insight from the patients' unique perspectives, not provided by quantitative outcomes.

The REVIVE trial specifically targeted exercise rehabilitation for the post hospital discharge phase of the ICU recovery pathway. The patients had diverse physical and psychological sequelae at baseline. Similar physical and psychological barriers have also been identified in a recent systematic review on factors that influence rehabilitation in ICU survivors. ${ }^{21}$ For some patients, these sequlae clearly impacted on benefits of the exercise programme and long-term continuation of unsupervised exercise after the programme had ended. Benefit from exercise rehabilitation might be more likely if both pre-existing and new co-morbidities such as pain, psychological sequelae and medication were managed optimally prior to entry into the exercise rehabilitation as well as during and after the programme. For example, with behaviour change techniques, appropriate medication, education or psychological support. There appears also to be the need for promotion of knowledge about critical illness sequlae to healthcare staff, general practitioners and community teams. This is important to achieve clinician belief in the importance of rehabilitation and commitment to changing practice which have been identified as facilitators of rehabilitation in ICU survivors. $^{21}$ 
One of the key facilitators of the benefits of the REVIVE exercise programme from the patient's perspective was the personalised nature of the programme. This personalised approach to treatment is well evidenced, for example, in tailoring drug therapy to phenotypic characteristics of patients, but it is a relatively unreported concept in therapy trials. A recent editorial highlighted the importance of planning personalised rehabilitation programmes which consider individual patients clinical, functional, environmental and social factors. ${ }^{22}$ The supervised nature of the exercise programme and the patient exercise manual were other key components of the programme that appeared to provide motivation and facilitate adherence. Previous self-directed, non-supervised exercise interventions, that placed the onus on the patient to exercise independently, with or without an exercise manual, did not demonstrate improved outcomes. ${ }^{11,12}$ Future trials should consider a personalised, rather than generic approach to exercise rehabilitation, with adequate health professional supervision, and the inclusion of a patient exercise manual as an aide to the supervised programme.

Patient feedback in this qualitative study indicates that the beneficial effects of short term supervised exercise programmes are not maintained long term. ${ }^{23}$ This is similar to many other populations such as respiratory patients attending pulmonary rehabilitation where the benefits also diminish post programme without follow-up/maintenance interventions ${ }^{23}$ Patients in this study indicated that the reasons for diminishing benefits post programme were mainly related to a lack of self-motivation in the absence of continued or further intervention, and in some cases low mood. The use of a diary for on-going exercise without supervision did not achieve commitment to on-going exercise. For future research, an exercise intervention should be refined to support continued exercise or physical activity for more than 6 weeks for behaviour change to occur. 
There is a need for consensus on outcome measures to use for this population. ${ }^{23}$ Significant work in defining appropriate patient-relevant core outcome sets are underway. ${ }^{25}$ Recently a consensus-based set of core outcome measures that are recommended for use in all research studies evaluating acute respiratory failure survivors after hospital discharge has been published. ${ }^{26,27} \mathrm{~A}$ unique element of this qualitative work is that patients' perceptions of the multiple quantitative outcome measures used in the REVIVE trial were explored. Patients themselves found it hard to articulate how the impact of the intervention should be measured highlighting why core outcome sets are both so important and challenging. In this study, getting back to previous health and life activities was one key goal for patients. This highlights the value of patient reported outcome measures. Patients also appeared to place value on measurements where they could get some instant feedback, indicating the importance of physical/performance based outcome measures. In addition, specific outcomes may be relevant to particular patients depending on their presentation at baseline, for example, sleep questionnaires for those with sleep difficulties, or evaluation of mood in those reporting feelings of depression. Outcome measures that are appropriate based on individual patient baseline presentation, the stage of recovery, the goals of the intervention, and what is meaningful to patients, are important to consider.

The results of this study were presented using thematic content analysis. This inductive approach allowed us to produce a detailed and systematic recording of the themes that emerged from the data and used the data itself to derive the structure of analysis, rather than a pre-determined framework. A limitation of this study was that participants in the control group were not interviewed. Although this was not one of the aims of this study, these participants could have provided insight into their perceptions of standard care after hospital discharge and allowed comparison of the study groups. 


\section{Conclusions}

This qualitative study adds an important perspective on the patient's attitude to an exercise intervention following recovery from critical illness, and provides insight into the potential facilitators and barriers to delivery of the programme and how programmes should be evolved for future trials. 


\section{Ethical approval}

The REVIVE trial was approved by the Northern Ireland Research Ethics Committee (ORECNI) (01/NI/0115). Written informed consent was provided by patients to take part in the REVIVE study which includes this qualitative work, and the procedures mentioned in the Participant Information Sheet. The Participant Information Sheet includes information about the qualitative semi structures interviews and plans to publish our results in medical journals.

\section{Availability of data and materials}

The data analysed during the current study are available from the corresponding author on request.

\section{Declaration of Conflicting Interests}

The authors declared no potential conflicts of interest with respect to the research, authorship, and/or publication of this article. 


\section{$\underline{\text { References }}$}

1. Herridge MS, Tansey CM, Matte A, Tomlinson G, Diaz-Granados N, Cooper A, Guest CB, Mazer D, Stewart TE, Kudlow P, Cook D, Slutsky AS, Cheung AM. Functional disability 5 years after acute respiratory distress syndrome. $N$ Engl J Med. 2011;364(4):1293-1304. doi: 10.1056/NEJMoa1011802.

2. O’Neill B, McAuley D. Sequelae and rehabilitation after critical illness. Clinical Medicine. 2011;11(6):609-614. doi: 10.7861/clinmedicine.11-6-609.

3. Cuthbertson BH, Roughton S, Jenkinson D, Maclennan G, Vale L. Quality of life in the five years after intensive care: a cohort study. Critical Care. 2010. doi:10.1186/cc8848.

4. Myhren H, Ekeberg O, Toien K, Karlsson S, Stokland O. Posttraumatic stress, anxiety and depression symptoms in patients during the first year post intensive care unit discharge. Critical Care. 2010. doi:10.1186/cc8870.

5. Connolly B, Salisbury L, O’Neill B, Geneen L, Douiri A, Grocott MP, Hart N, Walsh TS, Blackwood B, ERACIP group. Exercise rehabilitation for recovery from critical illness following intensive care unit discharge. Cochrane Database of Systematic Reviews. 2015; (6):CD008632. doi:10.1002/14651858.CD008632.pub2.

6. McWilliams D, Benington SM, Atkinson D. Outpatient based physical rehabilitation for survivors of prolonged critical illness: A randomised controlled trial. Physiotherapy Theory and Practice. 2016;32(3):179-190. doi: 10.3109/09593985.2015.1137663.

7. Jones C, Eddleston J, McCairn A, Dowling S, McWilliams D, Coughlan E, Griffiths RD. Improving rehabilitation following critical illness through outpatient physiotherapy classes and essential amino acid supplement: a randomised, controlled trial. J Crit Care. 2015; 30(5):901-7. doi:10.1016/j.jcrc.2015.05.002. 
8. Batterham AM, Bonner S, Wright J, Howell, SJ, Hugill K, Danjoux G. Effect of supervised aerobic exercise rehabilitation on physical fitness and quality-of-life in survivors of critical illness: an exploratory minimized controlled trial (PIX study). British Journal of Anaesthesia. 2014; 113(1):130-7. doi:10.1093/bja/aeu051.

9. Denehy L, Skinner EH, Edbrooke L, Haines K, Warrillow S, Hawthorne G, Gough K, Hoorn SV, Morris ME, Berney S. Exercise rehabilitation for patients with critical illness: a randomised controlled trial with 12 months follow up. Critical Care. 2013. doi:10.1186/cc12835.

10. Jackson JC, Ely EW, Morey MC, Anderson VM, Denne LB, Clune J, Siebert CS, Archer KR, Torres R, Janz D, Schiro E, Jones J, Shintani AK, Levine B, Pun BT, Thompson J, Brummel NE, Hoenig H. Cognitive and physical rehabilitation of intensive care unit survivors: results of the RETURN randomized controlled pilot investigation. Crit Care Med. 2012; 40(4):1088-1097. doi: 10.1097/CCM.0b013e3182373115.

11. Elliot D, McKinley S, Alison J, Aitken LM, King M, Leslie GD, Kenny P, Taylor P, Foley R, Burnmeister E. Health-related quality of life and physical recovery after a critical illness: a multi-centre randomised controlled trial of a home-based physical rehabilitation programme. Critical Care. 2011. doi:10.1186/cc10265.

12. Cuthbertson BH, Rattray J, Campbell MK, Gager M, Roughton S, Smith A, Hull A, Breeman S, Norrie J, Jenkinson D, Hernández R, Johnston M, Wilson E, Waldmann C, Practical study group. The PRaCTICaL study of nurse led, intensive care follow-up programmes for improving long term outcomes from critical illness: a pragmatic randomised controlled trial. BMJ. 2009. doi:10.1136/bmj.b3723. 
13. Jones C, Skirrow P, Griffiths RD, Humphris GH, Ingleby S, Eddleston J, Waldmann C, Gager M. Rehabilitation after critical illness: a randomised controlled trial. Crit Care Med. 2003; 31(10):2456-2461. doi: 10.1097/01.CCM.0000089938.56725.33.

14. McDowell K, O’Neill B, Blackwood B, Clarke C, Gardner E, Johnston P, Kelly M, McCaffrey J, Mullan B, Murphy S, Trinder TJ, Lavery G, McAuley DF, Bradley JM. Effectiveness of an exercise programme on physical function in patients discharged from hospital following critical illness: a randomised controlled trial (the REVIVE trial). Thorax. 2016. doi:10.1136/thoraxjnl-2016-208723.

15. Walker W, Wright J, Danjoux G, Howell SJ, Martin D, Bonner S. Project Post Intensive Care eXercise (PIX): a qualitative exploration of intensive care unit survivors' perception of quality of life post-discharge and experience of exercise rehabilitation. Journal of the Intensive Care Society. 2015;16(1):37-44. doi: $10.1177 / 1751143714554896$.

16. Medical Research Council. Development and evaluating complex interventions: new guidance. $\underline{\text { www.mrc.ac.uk/complexinterventionsguidance }}$. Accessed Oct 2016.

17. Lewin S, Glenton G, Oxman AD. Use of qualitative methods alongside randomised controlled trials of complex healthcare interventions: methodological study. BMJ 2009. doi:10.1136/bmj.b3496.

18. Tong A, Sainsbury P, Craig J. Consolidated criteria for reporting qualitative research (COREQ): a 32-item checklist for interviews and focus groups. International Journal for Quality in Health Care. 2007; 19(6):349-357. doi:10.1093/intqhe/mzm042.

19. Burnard P, Gill P, Stewart K, Treasure E, Chadwick B. Analysing and presenting qualitative data. Br Dent J. 2008; 204(8):429-432. doi:10.1038/sj.bdj.2008.292.

20. Burnard P. A method of analysing interview transcripts in qualitative research. Nurse Education Today. 1991; 11(6):461-66. 
21. Parry SM, Knight LD, Connolly B, Baldwin C, Puthucheary Z, Morris P, Mortimore J, Hart N, Denehy L, Granger CL. Factors influencing physical activity and rehabilitation in survivors of critical illness: a systematic review of quantitative and qualitative studies. Intensive Care Med. 2017; 43(4):531-542. doi: 10.1007/s00134017-4685-4.

22. Ambrosino N, Clini EM. Response to pulmonary rehabilitation: toward personalised programmes? Eur Respir J. 2015; 46:1538-1540. doi:10.1183/13993003.01125-2015.

23. Busby AK, Reese RL, Simon SR. Pulmonary rehabilitation maintenance interventions: a systematic review. American Journal of Health Behaviour. 2014; 38(3):321-330. doi:10.5993/AJHB.38.3.1.

24. Needham DM, Davidson J, Cohen H, Hopkins RO, Weinert C, Wunsch H, Zawistowski C, Bemis-Dougherty A, Berney SC, Bienvenu OJ, Brady SL, Brodsky MB, Denehy L, Elliott D, Flatley C, Harabin AL, Jones C, Louis D, Meltzer W, Muldoon SR, Palmer JB, Perme C, Robinson M, Schmidt DM, Scruth E, Spill GR, Storey CP, Render M, Yotto J, Harvey M. Improving long-term outcomes after discharge from intensive care unit: report from a stakeholders' conference. Crit Care Med. 2012; 40(2):502-9. doi:10.1097/CCM.0b013e318232da75.

25. Blackwood B, Marshall J, Rose L. Progress on core outcomes sets for critical care research. Current Opinion in Critical Care. 2015; 21(5);439-444. doi: 10.1097/MCC.0000000000000232.

26. Turnbull AE, Sepulveda BA, Dinglas VD, Chessare CM, Bingham CO, Needham DM. Core Domains for Clinical Research in Acute Respiratory Failure Survivors: An international Delphi Consensus Study. Crit Care Med. 2017; 45(6):1001-1010. doi: 10.1097/CCM.0000000000002435. 
27. Needham DM, Sepulveda KA, Dinglas VD, Chessare CM, Aronson Friedman L, Bingham CO, Turnbull AE. Core outcome Measures for Clinical Research in Acute Respiratory Failure Survivors: An International Modified Delphi Consensus Study. Am J Respir Crit Care Med. 2017: doi: 10.1164/rccm.201702-0372OC. [Epub ahead of print] 


\section{$\underline{\text { Tables }}$}

Table 1. Outline of the interview schedule*

\section{Interview Schedule Questions}

How do you feel the exercise programme has affected your health?

Do you think your relatives/carers/friends see a difference in you?

How satisfied were you with the exercise programme?

What suggestions if any, would you give for the exercise programme?

Do you think the exercise programme has helped you to continue with the exercise or physical activity in the past 6 months?

How confident are you that you could continue to exercise or do physical activity on your own or in the future?

This research wanted to test how the exercise programme affected you. What do you think would be the best way of testing or measuring how the programme affected you?

During the information collecting sessions with the research nurse you did a number of questionnaires, two hand tests and a walk test. How did you find these?

Would you recommend the exercise programme to anyone else who has had a stay in intensive care?

Is there anything else that you would like to add regarding your experiences of taking part in the study?

*The patient exercise manual, copies of the questionnaires and photographs of the physical outcome measures from the REVIVE trial were used as cues to facilitate reference to relevant sections of the interview. 
Table 2. Location of interview and characteristics of interviewed patients and the total intervention group of the REVIVE trial

\begin{tabular}{|l|l|l|}
\hline Location of interview/ & Interviewed & Total \\
Characteristic & patients & intervention \\
group n=30
\end{tabular}




\section{Figure Legends}

[Figure 1. Participant flow diagram] 


\section{$\underline{\text { Appendices }}$}

Appendix A. Summary of qualitative analysis method.

A summary of the qualitative analysis procedure used in the REVIVE study. This was based on Burnard's description of thematic content analysis ${ }^{1,2}$

1. Burnard P, Gill P, Stewart K, Treasure E, Chadwick B. Analysing and presenting qualitative data. Br Dent J. 2008; 204(8):429-432.

2. Burnard P. A method of analysing interview transcripts in qualitative research. Nurse Education Today. 1991; 11(6):461-66. 